\title{
Pemodelan Inversi Gravitasi 4d Injeksi Gas Pada Reservoir Minyak
}

\author{
Muhammad Zuhdi ${ }^{1}$, Ari Setiawan ${ }^{2}$ \\ 1. Program Studi Pendidikan Fisika Universitas Mataram \\ 2. Program Studi Geoisika Universitas Gadjah Mada Yogyakarta \\ Email : zuhdiunram@gmail.com
}

\begin{abstract}
Injeksi fluida pada reservoir minyak dapat meningkatkan produksi minyak. Injeksi ini perlu di identifikasi agar tidak merugikan. Salah satu upaya identifikasi injeksi fluida pada reservoir minyak adalah pemantauan dengan mikro gravitasi $4 D$. Injeksi gas berupa uap air (steam) pada reservoir melalui sumur minyak dapat meningkatkan produksi di sumur-sumur sekitarnya, dengan asumsi gas akan mendorong minyak menuju sumur produksi. Injeksi ini memerlukan identifikasi gerak fluida agar efeknya tidak merugikan. Geometri fluida injeksi pada titik sumur minyak dapat didekati dengan bentuk bola (sphere), sedangkan pergerakan fluida dengan arah tertentu dapat di dekati dengan bentuk silinder. Program inversi dengan matlab telah dibuat untuk kepentingan tersebut. Hasil inversi menunjukkan dapat ditentukannya pusat bola dan silinder, jari-jari bola maupun silinder serta panjang silinder dari kedua model tersebut.
\end{abstract}

Keywords: Pemodelan, inversi, injeksi gas, reservoir.

\section{PENDAHULUAN}

Kebutuhan minyak dunia selalu meningkat dari waktu ke waktu, sementara ketersediaan minyak semakin menipis. Upaya untuk mencukupi kebutuhan minyak dilakukan dengan cara eksplorasi sumber minyak baru dan optimalisasi reservoir minyak yang telah berproduksi. Salah satu cara untuk meningkatkan produksi adalah dengan menginjeksi fluida ke dalam reservoir. Fluida ini akan bergerak menjauhi sumur injeksi dan mendorong minyak menuju sumur produksi. [1]

Injeksi fluida dapat merugikan apabila fluida langsung bergerak menuju sumur produksi sehingga produksi akan terhenti. Untuk mencegah hal tersebut perlu dilakukan upaya identifikasi injeksi fluida pada reservoir melaui pemantauan dengan metoda geofisika mikro gravitasi 4D. [2]

Injeksi gas berupa uap air pada reservoir melalui sumur minyak dapat meningkatkan produksi di sumursumur sekitarnya, dengan asumsi gas akan mendorong minyak menuju sumur produksi dengan arah radial dan jejari seragam. Dorongan ini akan menghasilkan akumulasi minyak di sumur produksi. Adakalanya fluida injeksi langsung bergerak menuju sumur produksi yang mengakibatkan produksi terhenti total karena fluida yang terhisap oleh sumur produksi adalah fluida injeksi tersebut. Untuk mencegah hal ini perlu dilakukan identifikasi gerak fluida. Geometri fluida yang diharapkan di sekitar sumur injeksi adalah bentuk bola (sphere), jika bentuk ini teridentifikasi maka injeksi berjalan aman. Fluida yang bergerak langsung ke arah tertentu menuju sumur produksi dapat di dekati dengan bentuk silinder, jika bentuk ini terdeteksi maka injeksi harus segera di hentikan.

Anomali gravitasi 4D akibat injeksi dengan selisih densitas positif ditunjukkan oleh gambar 1. Selisih densitas positif artinya fluida injeksi memiliki densitas lebih besar dari fluida pengisi reservoir. Pada penelitian ini selisih densitasnya bernilai negatif karena fluida injeksi berupa gas.

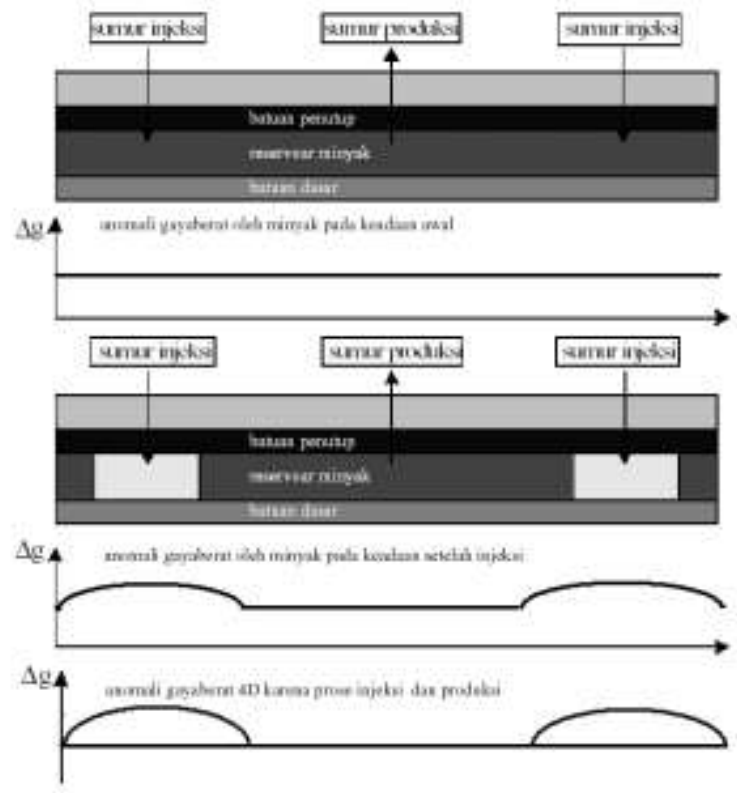

Gambar 1. Respon gravitasi 4D akibat injeksi fluida pada reservoir (Minardi,2002)

Program inversi dengan matlab telah dibuat untuk kepentingan identifikasi tersebut. Hasil inversi yang berupa geometri bola dan geometri silinder horizontal menunjukkan dapat ditentukannya pusat bola dan silinder, jari-jari bola dan silinder dari model serta panjang silinder horizontal dari model tersebut.

Injeksi gas yang sesuai dengan harapan adalah berbentuk bola sebagaimana tampak pada gambar 2.a. sedangkan injeksi gas yang langsung menuju sumur 
injeksi adalah berbentuk silinder sebagaimana tampak pada gambar 2.b. Kedalaman injeksi sebesar z, jari-jari bola maupun silinder sebesar R, selisih densitas adalah $\Delta$ rho. Pada gambar 2.A sumbu $\mathrm{x}$ sejajar bidang gambar. Pada gambar 2.B sumbu x tegak lurus bidang gambar, sumbu y sejajar gambar dengan pusat silinder pada $\mathrm{y}=0$. Panjang silinder total adalah $2 \mathrm{~L}$.
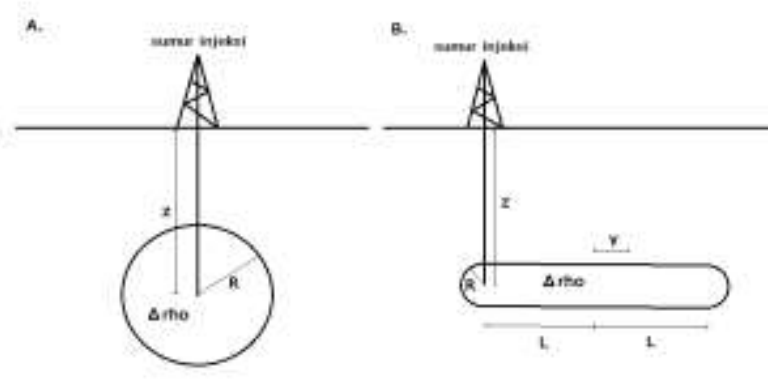

Gambar 2. Injeksi gas pada reservoir A. berbentuk bola. $\boldsymbol{B}$. berbentuk silinder

\section{TINJAUAN PUSTAKA}

Injeksi fluida berupa gas (uap air/steam) yang di injeksian pada reservoir melaui sumur minyak dapat di anggap memiliki bentuk geometri bola (sphere). Respon nilai gravitasi di permukaan akibat anomali bentuk bola ini dapat di tuliskan sebagai [3]:

$$
\mathrm{g}=4 \pi \mathrm{G} \Delta \rho \mathrm{R}^{3} / 3\left(\mathrm{x}^{2}+\mathrm{z}^{2}\right)^{3 / 2}
$$

sehingga nilai gravitasi maksimum nya:

$$
\mathrm{g}=4 \pi \mathrm{G} \Delta \rho \mathrm{R}^{3} / 3\left(\mathrm{x}^{2}+\mathrm{z}^{2}\right)^{3 / 2}
$$

$\mathrm{G}$ adalah tetapan gravitasi Newton, $\Delta \rho$ adalah selisih densitas sebelum dan sesudah injeksi, $\mathrm{R}$ adalah jari-jari bola, $\mathrm{x}$ adalah jarak horizontal titik pengukuran serta $\mathrm{z}$ adalah kedalaman pusat injeksi. Detil keterangan dapat dilihat pada gambar 2.A.

Nilai gravitasi maksimum terjadi pada $\mathrm{x}=0$ atau tepat di atas pusat bola.

Injeksi fluida berupa gas (uap air/steam) bergerak langsung menuju sumur produksi dapat di anggap memiliki bentuk geometri silinder horizontal dengan sumbu silinder sejajar dengan arah pergerakan fluida. Respon nilai gravitasi di permukaan akibat anomali bentuk silinder horizontal ini dapat di tuliskan sebagai [3]:

$$
g=\frac{G \pi R^{2} \Delta \rho}{z\left(1+\frac{x^{2}}{z^{2}}\right)}\left[\frac{1}{\left(1+\frac{x^{2}+z^{2}}{(y+L)^{2}}\right)^{1 / 2}}-\frac{1}{\left(1+\frac{x^{2}+z^{2}}{(y-L)^{2}}\right)^{1 / 2}}\right]
$$

sehingga nilai gravitasi maksimumnya akan terjadi di atas sumbu silinder dengan nilai:

$$
g=\frac{G \pi R^{2} \Delta \rho}{z}\left[\frac{1}{\left(1+\frac{z^{2}}{(y+L)^{2}}\right)^{1 / 2}}-\frac{1}{\left(1+\frac{z^{2}}{(y-L)^{2}}\right)^{1 / 2}}\right]
$$

$\mathrm{G}$ adalah tetapan gravitasi Newton, $\Delta \rho$ adalah selisih densitas sebelum dan sesudah injeksi, $\mathrm{R}$ adalah jari-jari silinder, $\mathrm{x}$ adalah jarak horizontal titik pengukuran diukur dari pusat silinder, y adalah jarak pusat pengukuran dari pusat silinder serta $\mathrm{z}$ adalah kedalaman pusat injeksi. Gambar 2.B menunjukkan nilai besaran tersebut.

\section{METODE PENELITIAN}

Teori inverse dapat dikatakan sebagai seni untuk mendapatkan berbagai parameter fisis dengan bekal pengetahuan yang cukup tentang pemodelan kedepan (forward modeling)[4].

Hubungan antara data hasil observasi dengan model dapat dituliskan sebagai:

$$
\mathrm{d}=\mathrm{g}(\mathrm{m})
$$

dengan $\mathrm{d}$ adalah data observasi, $\mathrm{m}$ adalah parameter model dan $g$ adalah fungsi forward yang merupakan fungsi prediksi dari model.

Jika data hasil observasi berjumlah $\mathrm{N}$ dan parameter model sejumlah $\mathrm{M}$ dapat dihubungkan dengan matrik kernel melalui persamaan:

$$
\mathrm{d}=\mathrm{Gm}
$$

dengan d adalah matrik berukuran $\mathrm{Nx} 1, \mathrm{G}$ adalah matrik kernel berukuran NxM dan m adalah parameter model berukuran Mx1. Hubungan inversi parameter model dengan data observasi dapat dituliskan menjadi:

$$
m=\left[G^{T} G\right]^{1} G^{T} d
$$

Nilai gravitasi terukur sebenarnya memiliki hubungan non linear terhadap parameter model yang di cari yaitu kontras densitas, jejari dan posisi, namun hubungan ini dapat di selesaikan dengan pendekatan linear. Prinsip metoda ini adalah LSQR yang dikembangkan secara khusus. Rumusan metoda inversi non-linier dengan pendekatan linier prinsipnya menggunakan deret Taylor suku pertama dan mengabaikan suku yang lebih tinggi dari deret Taylor di sekitar $\mathrm{x}+\Delta \mathrm{x}$ sebagai berikut:

$$
\mathrm{f}_{(\mathrm{x}+\Delta \mathrm{x})}=\mathrm{f}_{(\mathrm{x})}+\mathrm{f}^{\prime}(\mathrm{x}) \Delta \mathrm{x}
$$


$\mathrm{f}_{(\mathrm{x}+\Delta \mathrm{x})}$ adalah data hasil pengukuran yang ditulis dengan $\mathrm{d}, \mathrm{f}_{(\mathrm{x})}$ adalah hasil perhitungan (respon model) yaitu $\mathrm{g}\left(\mathrm{m}_{0}\right)$ dan $\mathrm{f}^{\prime}{ }_{(\mathrm{x})}$ turunan pertama parameter model yang membentuk matriks Jacobi yang ditulis $\mathbf{J}_{0}$, sehingga:

$$
\mathrm{d}=\mathrm{g}\left(\mathrm{m}_{0}\right)+\mathrm{J}_{0} \Delta \mathrm{m}_{0}
$$

dengan nilai matrik Jacobi:

$$
J_{0}=\left[\frac{\partial g_{i}}{\partial m_{j}}\right]_{m o}
$$

dengan $\mathrm{m}=\mathrm{m}_{0}$ dan $\Delta \mathrm{m}=\left[\mathrm{m}-\mathrm{m}_{0}\right]$ dan $\mathrm{m}$ adalah parameter model yang di cari.

Untuk model Bola, matrik Jacobinya terdiri dari:

$$
J_{\rho}=\left[\frac{\partial g_{i}}{\partial \rho}\right]_{m o} \text { dan } J_{x}=\left[\frac{\partial g_{i}}{\partial x}\right]_{m o}
$$

dengan $\rho$ adalah kontras densitas dan $\mathrm{x}$ adalah posisi pusat bola, sehingga matrik Jacobi model bola dapat dituliskan sebagai:

$$
\mathbf{J}_{0}=\left[\begin{array}{ll}
\mathbf{J}_{\rho} & \mathbf{J}_{\mathrm{x}}
\end{array}\right]
$$

Dari persamaan (9) didapatkan:

$$
\mathrm{d}-\mathrm{g}\left(\mathrm{m}_{0}\right)=\mathrm{J}_{0} \Delta \mathrm{m}
$$

sehingga,

$$
\Delta \mathrm{m}=\left[\mathrm{J}_{0}^{\mathrm{T}} \mathrm{J}_{0}\right]^{-1} \mathrm{~J}_{0}^{\mathrm{T}}\left(\mathrm{d}-\mathrm{g}\left(\mathrm{m}_{0}\right)\right)
$$

dengan $\mathrm{J}_{\mathrm{o}}{ }^{\mathrm{T}}$ adalah transpose dari matrik $\mathrm{J}_{0}$.

Jika

$$
\mathrm{d}-\mathrm{g}\left(\mathrm{m}_{0}\right)=\Delta \mathrm{d}
$$

Maka $\Delta \mathrm{d}$ memiliki hubungan linear dengan $\Delta \mathrm{m}$ sehingga dapat diselesaikan dengan metode LSQR.

Prinsip penyelesaian inversi linear adalah hitungan berulang yang akan menghasilkan nilai $m=m_{0}+\Delta m$ sehingga didapatkan nilai $\Delta \mathrm{d}$ minimum. Dengan nilai RMS dari $\Delta$ d sangat kecil dengan batas tertentu, iterasi kemudian dihentikan. Dengan nilai $\Delta \mathrm{d}$ yang sangat kecil maka nilai $\mathrm{m} \approx \mathrm{m}_{0}$ sehingga parameter model sangat dekat dengan nilai sesungguhnya [5].

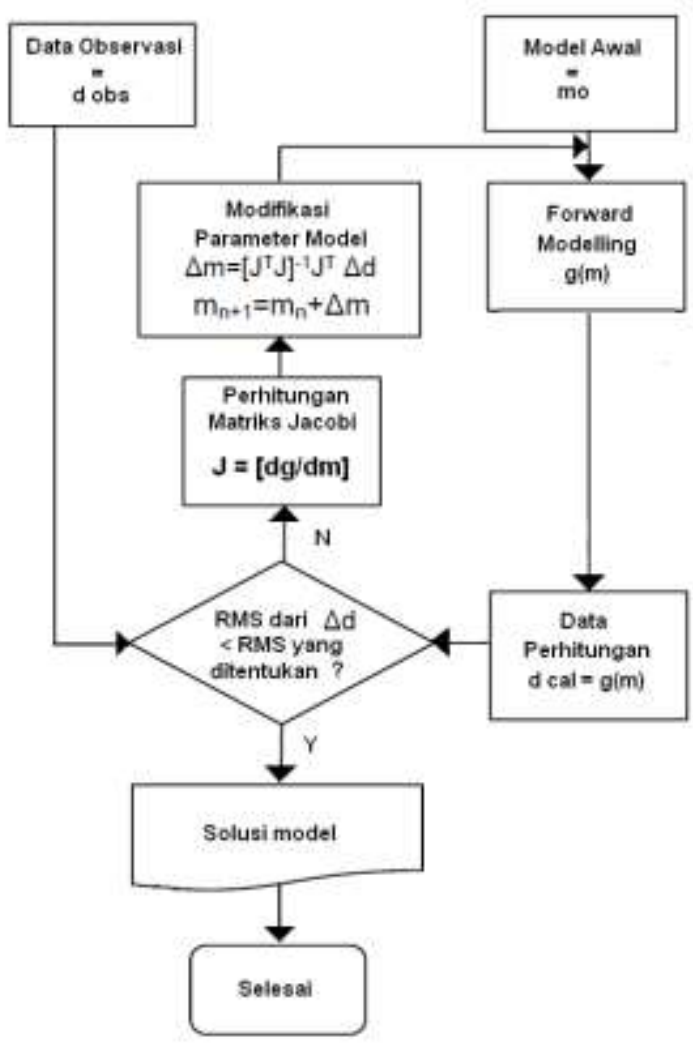

\section{Gambar 3. Flowchart Pemodelan Inversi}

Gambar 3 menunjukkan Flowchart Model Inversi yang dilakukan untuk mendapatkan model akhir. $\Delta \mathrm{d}$ dibuat agar nilainya minimum sehingga nilai model hasil inversi memiliki nilai yang sedekat mungkin dengan data.

Data yang digunakan pada penilitian ini adalah data sintetik (hasil dari pemodelan ke depan). Pada model bola maupun model silinder masing-masing dibuat 3 data sintetik . Pada model bola data pertama adalah hasil model forward tanpa noise, data kedua adalah model forward dengan noise hingga 40 mikrogal sedangkan data ketiga adalah forward model dengan noise hingga 80 mikrogal. Pada model silinder data pertama adalah hasil model forward tanpa noise, data kedua adalah model forward dengan noise hingga 10 mikrogal sedangkan data ketiga adalah forward model dengan noise hingga 20 mikrogal. Penambahan noise pada model-model tersebut dimaksudkan untuk menguji kemampuan dan kestabilan program inversi dalam mendapatkan parameter model hasil inversi. Noise pada kasus injeksi gas pada reservoir biasanya merupakan anomaly 4D dangkal yang terjadi akibat kenaikan atau penurunan muka air tanah yang tidak seragam dari satu titik pengukuran ke pengukuran yang lain. Noise pada data sentitik dibuat dengan cara membangkitkan nilai random yang digerser menjadi nilai positif dan negative kemudian dikalikan besaran noise hingga beberapa puluh mikrogal. 


\section{HASIL DAN PEMBAHASAN}

\section{Inversi Pada Model Bola}

Nilai gravitasi pada titik pengukuran pada model bola dituliskan sebagaimana persamaan (1) . Titik pusat bola dianggap sebagai titik pusat injeksi yang tidak berubah, sehingga pergerakan material injeksi bersifat konsentris karena batuan reservoir dianggap sebagai medium yang homogen dan isotropis. Densitas (rho) adalah kontras densitas batuan yang porinya terisi minyak dan air dengan batuan reservoir yang terisi fluida injeksi.

Parameter model yang dicari pada inversi ini adalah pusat bola dan jari-jari bola. Batuan reservoir yang sebelumnya terisi oleh air dan minyak (densitas campurannya $0,5 \mathrm{~g} / \mathrm{cc}$ ) diganti oleh gas yang densitasnya nol. Jika porositas batuan reservoir adalah $50 \%$ maka selisih densitasnya menjadi $0,45 \mathrm{~g} / \mathrm{cc}$. Jarijari bola injeksi berubah sesuai dengan jumlah material gas yang diinjeksikan.

Pada pemodelan ini nilai densitasnya $-0.45 \mathrm{~g} / \mathrm{cc}$. Posisi awal pusat bola 1000meter dan jari-jari awal model sebesar 450 meter dan kedalaman ijeksi sebesar 280 meter.

Dari hasil pemodelan inversi terhadap data tanpa noise didapatkan nilai posisi pusat bola 800 meter, sedangkan jari-jari bola 150 meter. Nilai ini didapatkan pada iterasi ke 11 dengan nilai RMS sebesar nol.

Perbandingan nilai hasil inverse untuk data tanpa noise, data dengan noise kecil dan data dengan noise besar ditunjukkan oleh tabel 1 .

Tabel. 1

\begin{tabular}{|c|c|c|c|}
\hline \multicolumn{4}{|c|}{ Hasil Inversi Model Bola } \\
\hline $\begin{array}{c}\text { Error } \\
(\mu \mathrm{Gal})\end{array}$ & $\begin{array}{c}\text { RMS } \\
(\mu \mathrm{Gal})\end{array}$ & $\begin{array}{c}\text { Jejari Bola } \\
(\text { meter })\end{array}$ & $\begin{array}{c}\text { Posisi Pusat } \\
\text { Bola (meter) }\end{array}$ \\
\hline 0 & 0 & 150,0000 & 800,0000 \\
\hline 20 & 5,5164 & 150,1029 & 800,6616 \\
\hline 40 & 9,4622 & 150,3865 & 799,6227 \\
\hline
\end{tabular}
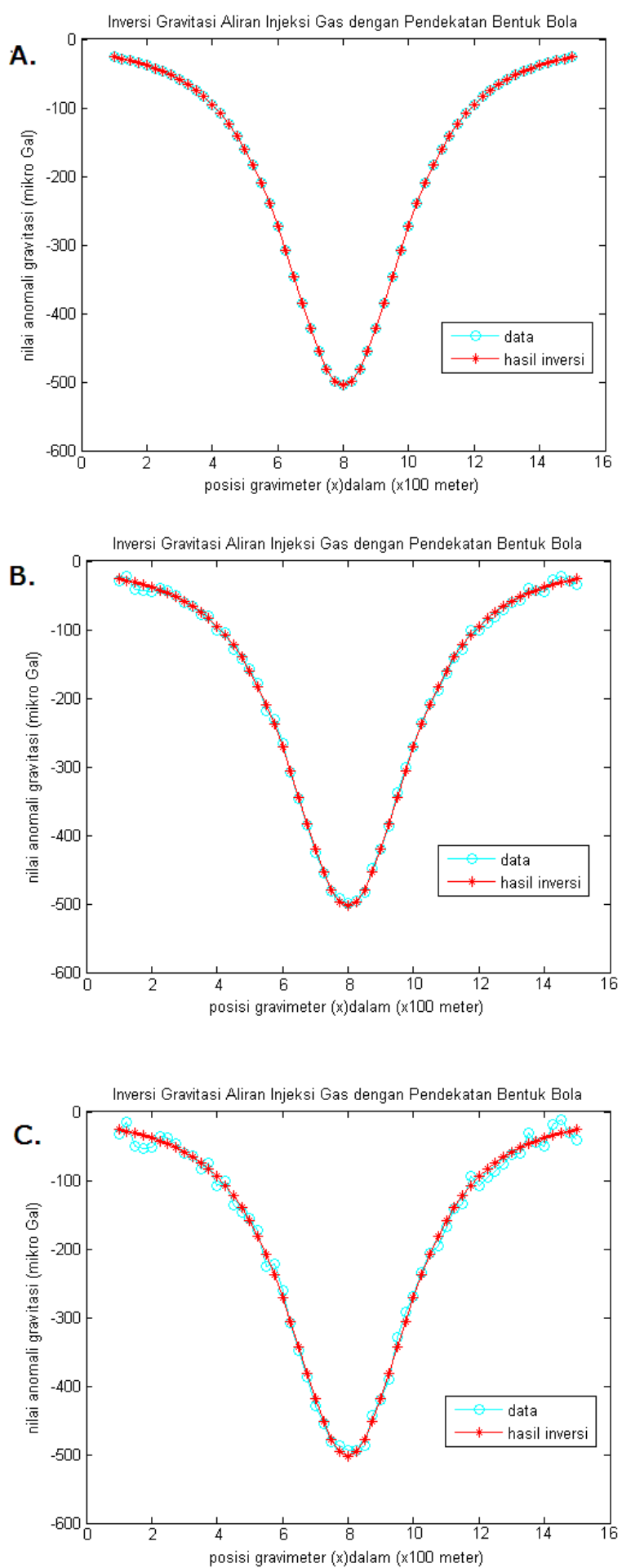

Gambar 4. Grafik hasil inversi bola. A. error 0 $\mu$ Gal B. error $20 \mu \mathrm{Gal} \mathrm{C.} \mathrm{error} 40 \mu \mathrm{Gal}$

\section{Inversi Pada Model Silinder}

Pada model ini material gas yang diinjeksikan tidak tersebar merata ke segala arah tetapi cenderung bergerak ke arah tertentu yang bentuknya dapat didekati dengan bentuk silinder horizontal. Nilai gravitasi pada titik pengukuran pada model silinder dituliskan sebagaimana persamaan (3) . 

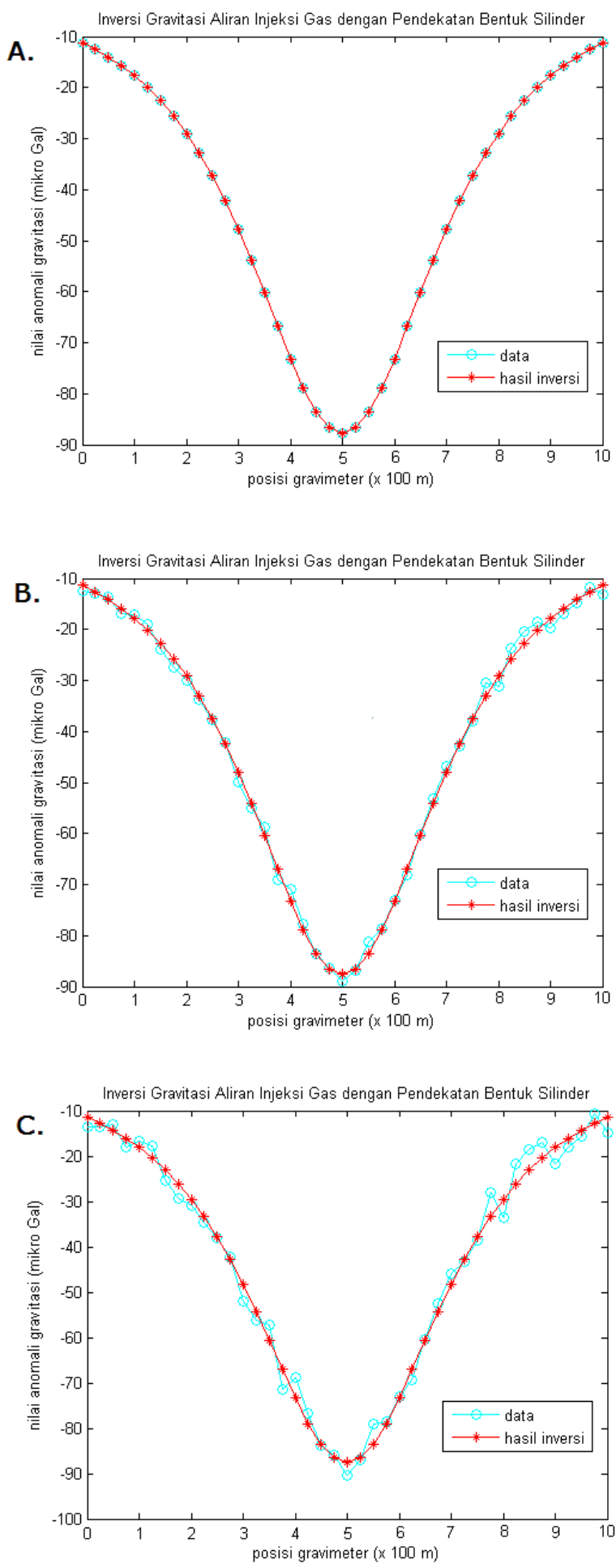

Gambar 5. Grafik hasil inversi silinder. A. error $0 \mu \mathrm{Gal}$ B. error $5 \mu \mathrm{Gal} \mathrm{C.} \mathrm{error} 10 \mu \mathrm{Gal}$

Perbandingan nilai hasil inverse untuk data tanpa noise, data dengan noise kecil dan data dengan noise besar ditunjukkan oleh table 2 .

Parameter model yang dicari pada inversi ini adalah selisih densitas, jari-jari silinder dan panjang silinder. Batuan reservoir yang sebelumnya terisi oleh air dan minyak (densitas campurannya $0,5 \mathrm{~g} / \mathrm{cc}$ ) diganti oleh gas yang densitasnya nol. Dengan menganggap porositas batuan reservoir adalah $50 \%$ maka selisih densitasnya menjadi $0,45 \mathrm{~g} / \mathrm{cc}$. Jari-jari silinder berubah sesuai dengan jumlah material gas yang diinjeksikan, demikian pula dengan perubahan panjang selinder.

Pada pemodelan ini nilai awal posisi pusat silinder adalah 600 meter. Jari-jari awal model sebesar 120 meter dan kedalaman ijeksi sebesar 320 meter.

Dari hasil pemodelan inversi didapatkan nilai pusat silinder 499,991 meter, sedangkan jari-jari silinder mendekati 149,991 meter dan panjang silinder 699,914 meter. Nilai ini didapatkan pada iterasi ke 30 dengan nilai RMS sebesar 0.0072 mikroGal..

Tabel. 2

\begin{tabular}{|l|l|l|l|l|}
\hline \multicolumn{5}{|c|}{ Hasil Inversi Model Silinder } \\
\hline $\begin{array}{l}\text { Error } \\
(\mu \text { Gal })\end{array}$ & $\begin{array}{l}\text { RMS } \\
(\mu \text { Gal) }\end{array}$ & $\begin{array}{l}\text { Posisi } \\
\text { Pusat } \\
\text { Silinder } \\
(\text { meter) }\end{array}$ & $\begin{array}{l}\text { Jejari } \\
\text { silinder } \\
\text { (meter) }\end{array}$ & $\begin{array}{l}\text { Panjang } \\
\text { Silinder } \\
\text { (meter) }\end{array}$ \\
\hline 0 & 0 & 499,9916 & 149,9916 & 699,9149 \\
\hline 5 & 1,5282 & 497,5686 & 150,7165 & 703,1848 \\
\hline 10 & 2,7439 & 500,7165 & 146,9293 & 691,5848 \\
\hline
\end{tabular}

\section{PENUTUP}

Dari hasil inversi dan nilai posisi pusat bola 800 meter, dan diameter bola 150 meter.

Dari hasil inversi nilai posisi pusat silinder mendekati 500 meter, jari-jari silinder mendekati 150 meter dan panjang silinder sebesar 7003 meter.

Semakin kecil nilai RMS yang disyaratkan, maka jumlah iterasinya semakin banyak. Nilai syarat RMS yang terlalu kecil akan mengakibatkan nilai tersebut tak terpenuhi sehingga iterasi terus berjalan tanpa henti. Untuk menghindari hal tersebut nilai RMS harus ditentukan dengan tepat.

\section{UCAPAN TERIMA KASIH}

Ucapan terima kasih kepada Aryono Adhi dan Agus Supriyanto yang telah membantu penulis dalam publikasi ilmiah ini. Jazakumullahu khoiron.

\section{REFERENSI}

[1]Zuhdi, M., , “Aplikasi Gaya Berat Mikro antar waktu Untuk Pemantauan Air Injeksi Pada Reservoir Minyak, Studi Kasus: "Lapangan Minyak X"”' Thesis Magister, ITB, Bandung. Pp 2-3, 2004

[2]Minardi, S, , Aplikasi Metoda Gayaberat Mikro 4D untuk Estimasi Porositas dan Saturasi, Thesis , Program Magister Teknik Geofisika Terapan ITB, Bandung, pp 45-46. 2002 
[3]Telford W.M. Gedart.L.P. Sheriff R.E.. Applied Geophysics. Second Edition Canbridge University Press, pp.57-77, 1990

[4]Richardson, R,M. Zandt, G. Inverse Problem in Geophysics, Department of Geosciences, University of Arizona, Tucson, Arizona, p 1-4. 2009

[5]Grandis. H.. Pengantar pemodelan Inversi Geofisika. Institute Teknologi Bandung, Himpunan Ahli Geofisika Indonesia, Bandung, p105-113,2009

\section{Biografi Penulis}

Muhammad Zuhdi ,memperoleh gelar Sarjana Sains (S.Si) di Jurusan Fisika FMIP UGM Yogyakarta, lulus tahun 1997. Memperoleh gelar Magister Teknik (M.T) Program Pasca Sarjana di Fakultas Ilmu Kebumian dan Teknologi Mineral, Institut Teknologi Bandung, lulus tahun 2014.Saat ini menjadi Dosen di Universitas Mataram dan melanjutkan studi program doktoral di Jurusan Fisika Universitas Gadjah Mada.

Ari Setiawan, memperoleh gelar Sarjana Sains (S.Si) di Jurusan Fisika FMIP UGM Yogyakarta, lulus tahun 1990. Memperoleh gelar Magister Sains (S.Si) di universitas yang sama. Memperoleh gelar Dr.-Ing. Dari Technischen Universitat Darmstadt Jerman. Saat ini mengajar di Jurusan Fisika Universitas Gadjah Mada Yogyakarta.

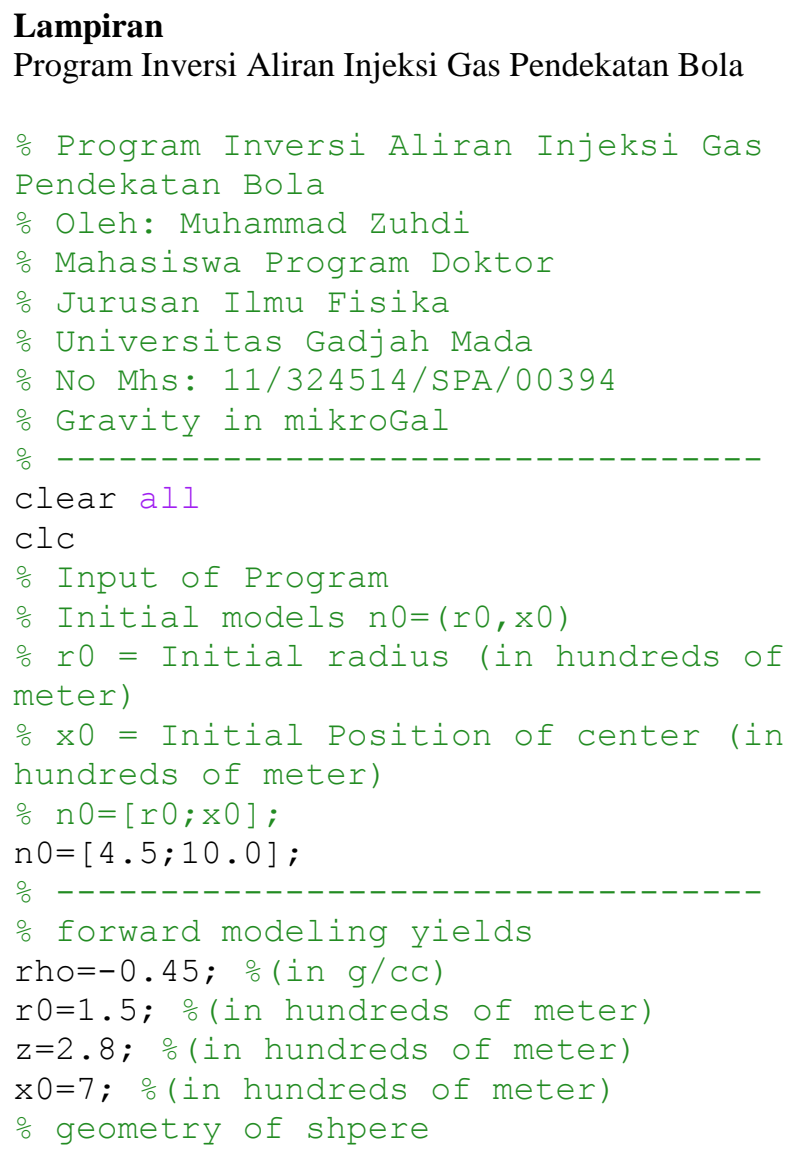

$\mathrm{w}=2792.5 ; \div \mathrm{w}=(4 / 3 * \mathrm{phi} * 6.672) * 100(\mathrm{in}$ micro Galls hectometer square per $\mathrm{kg}$ ) $\mathrm{x}=[0: 0.25: 16] ; \%$ (in hundreds of meter) \% observed data, r, $x, z$ are in hundreds of meter

$\mathrm{d} 1=\left(\mathrm{w}^{\star} \mathrm{z}^{\star} \mathrm{r} 0^{\wedge} 3^{\star} \mathrm{rho}\right) . /(((\mathrm{x}-$

$\left.\left.\mathrm{x} 0) \cdot{ }^{\wedge} 2+(\mathrm{z}) \cdot{ }^{\wedge} 2\right) \cdot \wedge 1.5\right)$;

$r=r a n d(1,57)$;

er $=(r-0.5)$;

$\mathrm{d}=\mathrm{d} 1+40 * e r$;

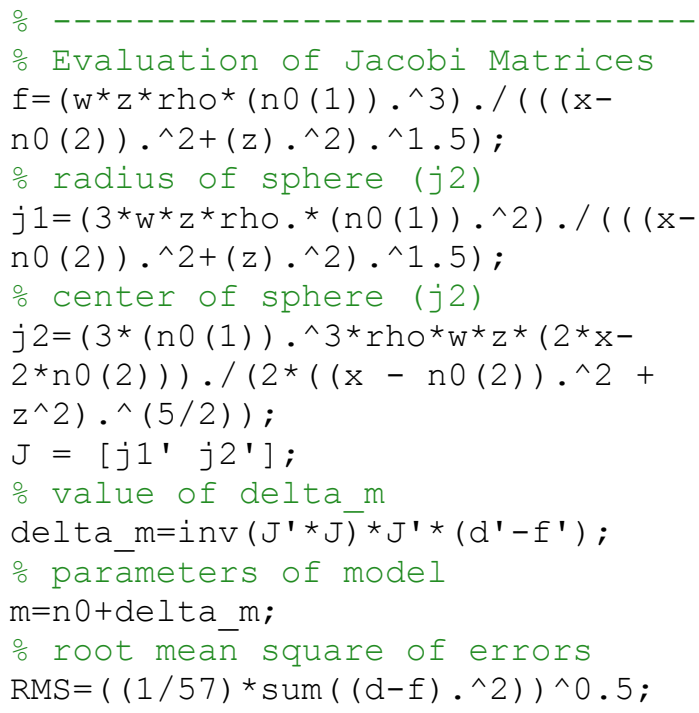


ylabel('nilai anomali gravitasi (mikro Gal)' )

legend('data', 'hasil inversi');

$i=i+1$;

iterasi $=i$

RMS

jejari_bola_dalam meter $=\mathrm{m}(1) \star 100$ end posisi_pusat_bola $=\mathrm{m}(2) * 100$

\author{
№ Error \\ \%iterasi $=11$ \\ $\therefore \mathrm{RMS}=0$ \\ \%jejari_bola_dalam_meter $=150$ \\ oposisi_pusat_bola ${ }^{-}=800$ \\ orror 20 mikroGal \\ oiterasi $=8$ \\ $\circ \mathrm{RMS}=5.5164$ \\ ojejari_bola_dalam meter $=150.1029$ \\ oposisi_pusat_bola $=800.6616$ \\ oEror 40 mikroGal \\ oiterasi $=8$ \\ $\div \mathrm{RMS}=9.4622$ \\ ojejari bola dalam meter $=149.8365$ \\ oposisi_pusat_bola $=799.6227$
}

\section{Program Inversi Aliran Injeksi Gas Pendekatan Silinder}

\footnotetext{
o Program Inversi Aliran Injeksi Gas Pendekatan silinder

\% Oleh: Muhammad Zuhdi

\% Mahasiswa Program Doktor

\% Jurusan Ilmu Fisika

\% Universitas Gadjah Mada

\% No Mhs: 11/324514/SPA/00394

- Model Parameter dalam meter

\% Gravity in mGal

clear

clc

\% Input of Program

- Initial models $\mathrm{n} 0=(\mathrm{x} 0, \mathrm{r} 0, \mathrm{~L} 0)$

\% $\mathrm{x} 0=$ Center of Cylinder (in g/Cc)

\% $r 0=$ Initial radius (in hundreds of meter)

\% LO = Initial length (in hundreds of meter)

$\mathrm{n} 0=[6 ; 1.2 ; 3.2]$;

\% forward modeling yields

$\mathrm{z}=1 ; \%$ (in hundreds of meter)

rho $=-0.45 ; \%$ (in $\mathrm{g} / \mathrm{CC}$ )

$\mathrm{x} 0=5 ; \circ$ (in hundreds of meter)

$r 0=1.5 ; \%$ (in hundreds of meter)

$\mathrm{L} 0=3.5 ; \%$ (in hundreds of meter)

$\mathrm{y}=1 ; \%($ in $\mathrm{g} / \mathrm{CC})$

$\mathrm{xx}=(0: 0.25: 10) ; \%$ (in hundreds of meter)

o geometry of cylinder

$\mathrm{w}=2090 ; \% \mathrm{w}=(\mathrm{phi} * 6.672) * 100$
}

observed data, r, $x, z$ are in hundreds of meter

$\mathrm{d} 1=\left(\mathrm{w}^{*} \mathrm{r} 0^{\wedge} 2 * \mathrm{rho} \mathrm{z} \cdot /\left(\mathrm{z}^{\wedge} 2+(\mathrm{xx}-\right.\right.$

$\left.\left.\mathrm{x} 0) \cdot{ }^{\wedge} 2\right)\right) \cdot{ }^{\star}\left(\left((\mathrm{y}+\mathrm{L} 0)^{\wedge} 2 \cdot /\left((\mathrm{y}+\mathrm{L} 0)^{\wedge} 2+((\mathrm{xx}-\right.\right.\right.$

$\left.\left.\left.\mathrm{x} 0) \cdot{ }^{\wedge} 2+\mathrm{z}^{\wedge} 2\right)\right)\right) \cdot{ }^{\wedge} 0 \cdot 5-\left((\mathrm{y}-\mathrm{L} 0)^{\wedge} 2 \cdot /\left(\left(\mathrm{y}^{-}\right.\right.\right.$

$\left.\left.\left.\mathrm{L} 0)^{\wedge} 2+\left((\mathrm{x} x-\mathrm{x} 0) \cdot{ }^{\wedge} 2+\mathrm{z}^{\wedge} 2\right)\right)\right) \cdot{ }^{\wedge} 0.5\right)$;

$r=r a n d(1,41)$;

er $=(r-0.5)$;

$\mathrm{d}=\mathrm{d} 1+10 *$ er;

o function of initial models

$\mathrm{f}=\left(\mathrm{w}^{\star} \mathrm{n} 0(2)^{\wedge} 22^{*} \mathrm{rho} \mathrm{z}^{*} \cdot /\left(\mathrm{z}^{\wedge} 2+(\mathrm{xx}-\right.\right.$ $\left.\left.\mathrm{n} 0(1)) \cdot{ }^{\wedge} 2\right)\right) \cdot{ }^{*}\left(\left((\mathrm{y}+\mathrm{n} 0(3))^{\wedge} 2 \cdot /\left((\mathrm{y}+\mathrm{n} 0(3))^{\wedge}\right.\right.\right.$ $\left.\left.2+\left((\mathrm{xx}-\mathrm{n} 0(1)) \cdot{ }^{\wedge} 2+\mathrm{z}^{\wedge} 2\right)\right)\right) \cdot{ }^{\wedge} 0 \cdot 5-((\mathrm{y}-$ $\mathrm{no}(3))^{\wedge} 2 . /\left((\mathrm{y}-\mathrm{n} 0(3))^{\wedge} 2+((\mathrm{xx}-\right.$

no (1)) $\left.\left.\left.\left.\cdot{ }^{\wedge} 2+z^{\wedge} 2\right)\right)\right) \cdot \wedge 0.5\right)$;

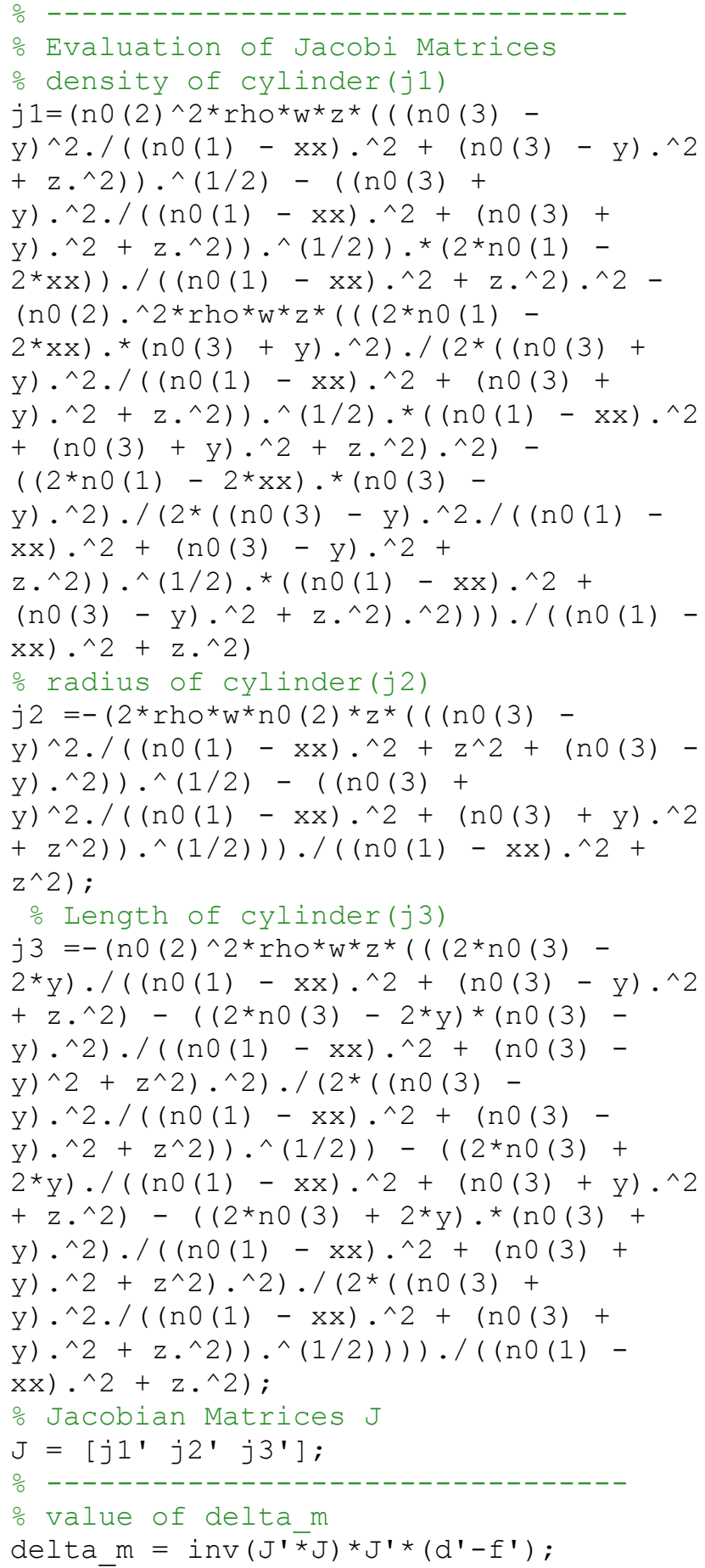




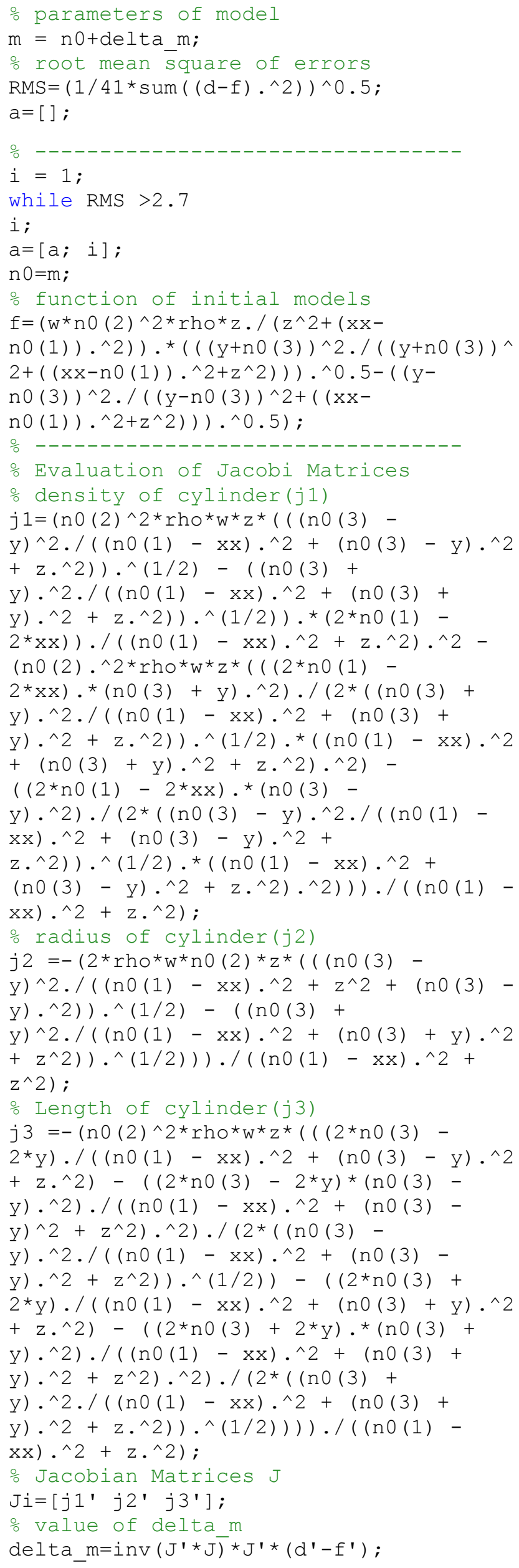

o parameters of model

$\mathrm{m}=\mathrm{n} 0+$ delta_m;

\% root mean square of errors

$\operatorname{RMS}=\left(1 / 41 * \operatorname{sum}\left((d-f) \cdot{ }^{\wedge} 2\right)\right)^{\wedge} 0.5$;

\% outputs of programs

model $=m^{\prime}$;

fmodel $=\left(w^{\star} \operatorname{model}(2)^{\wedge} 2{ }^{*} r h o * z \cdot /\left(z^{\wedge} 2+(x x-\right.\right.$ model $\left.\left.(1)) \cdot{ }^{\wedge} 2\right)\right) \cdot{ }^{\star}\left(\left((y+\operatorname{model}(3))^{\wedge} 2 \cdot /((y+m\right.\right.$ $\operatorname{odel}(3))^{\wedge} 2+((x x-$

model (1)) $\left.\left.\left.\cdot{ }^{\wedge} 2+z^{\wedge} 2\right)\right)\right) \cdot \wedge 0 \cdot 5-\left(\left(y^{-}\right.\right.$

model (3) )^2./((y-model (3) $)^{\wedge} 2+((x x-$

model (1)) $\left.\left.\left.\left.\cdot \wedge 2+z^{\wedge} 2\right)\right)\right) \cdot \wedge 0.5\right)$;

figure (2)

plot ( $x x, d,{ }^{\prime} O c^{-} ', x x$, fmodel, '* $\left.r-'\right)$

o Titling

title('Inversi Gravitasi Aliran Injeksi Gas dengan Pendekatan Bentuk Silinder') xlabel('posisi gravimeter (x $100 \mathrm{~m}$ )') ylabel('nilai anomali gravitasi (mikro Gal) ')

legend('data', 'hasil inversi');

$i=i+1 ;$

iterasi $=i$

RMS

posisi_pusat_silinder $=$ model $(1) * 100$

radius_silider_dalam_meter $=$ model $(2) * 100$

panjang_silinder_dalam_meter $=$ model $(3) * 2$ 00

end

№ Error

oiterasi $=30$

$\because \mathrm{RMS}=0.0072$

oposisi_pusat_silinder $=499.9916$

oradius_silider dalam meter $=149.9845$

opanjang_silinder_dalām_meter =

699.9149

oError 5 mikroGal

oiterasi $=15$

RMS $=1.3997$

oposisi_pusat silinder $=497.5686$

oradius silider dalam meter $=150.7165$

opanjang_silindēr_dalām_meter =

703.1848

oError $10 \mathrm{mikroGal}$

\%iterasi $=14$

$\circ \mathrm{RMS}=2.6787$

oposisi_pusat_silinder $=500.0143$

oradius_silidēr_dalam_meter $=146.9293$

opanjang_silindē__dalām_meter = 691.5848 